\title{
Federal suicide prevention framework underwhelms
}

Cite as: CMAJ 2017 January 16;189:E96-7. doi: 10.1503/cmaj.109-5367

F our years after passing legislation to create it, the federal government has quietly tabled a suicide prevention framework as it announced plans for a national phone, text and chat service that will link existing crisis hotlines and distress centres to a single toll-free number nationwide.

The Public Health Agency of Canada mentioned the framework, "Working Together to Prevent Suicide," in a news release about the crisis line service. There was no separate announcement about the framework itself, although Health Minister Dr. Jane Philpott tweeted about its release.

As the document acknowledges, the framework is not a suicide prevention strategy of the kind both the World Health Organization and CMAJ have called on Ottawa to implement. The new framework was not accompanied by funding, does not include goals, time lines or specific activities intended to reduce suicides, and does not assign responsibility for any multi-jurisdictional actions.

Instead, the document summarizes federal suicide prevention activities and states that it is intended to help "connect suicide prevention efforts across Canada and serve as the foundation for meaningful and lasting partnerships across sectors, organizations and jurisdictions to prevent suicide."

The framework states that the federal government will continue to work with the provinces and territories, Indigenous organizations, refugee groups and other stakeholders to support suicide prevention, but does not provide details.

Nearly 4000 Canadians take their own lives every year, according to Health Canada. That figure is likely vastly underreported, suicide prevention researchers say. Rates of suicide are an estimated five-six times the national average for First Nations youth and confirmed to be up to 25 times the national average for Inuit in Labrador.

Several researchers and Inuit leaders called on the federal government to follow the framework with further, concrete actions and resources - and an actual strategy.

"The omission of an action around the creation of a national strategy is disappointing, especially considering the emphasis that Inuit have placed on a national strategy as the centrepiece for

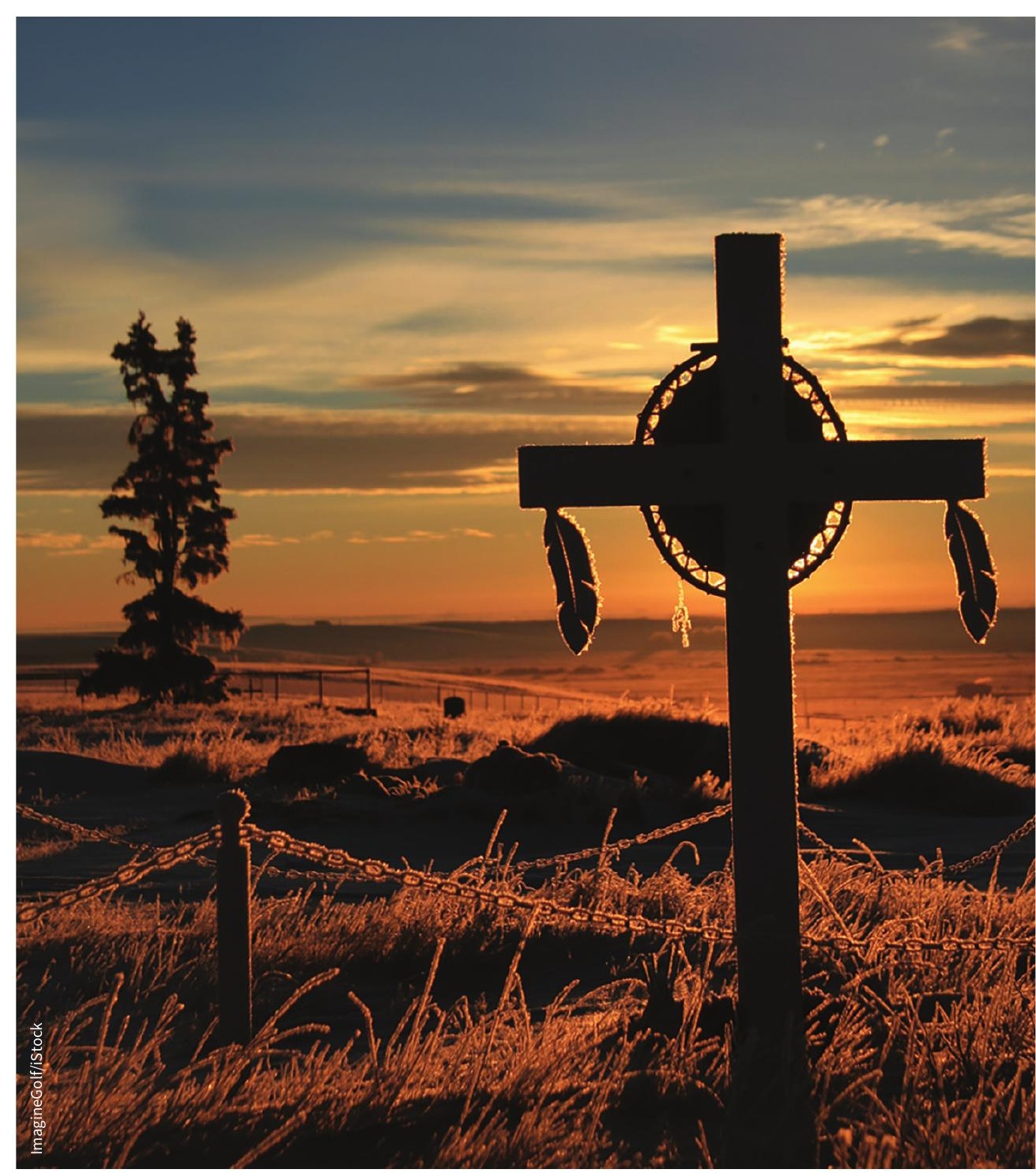

Rates of suicide are an estimated five-six times the national average for First Nations youth. 
action on suicide prevention," says Natan Obed, president of Inuit Tapiriit Kanatami, the national Inuit organization.

"The reasons for having a national strategy are laid out in a number of different WHO evidence-based documents, and also the success of some countries in decreasing the rate of suicide through targeted implementation of a national strategy," Obed added. "We have evidence that national strategies work."

Obed is optimistic, however, that the federal government will work with his organization, other Indigenous leaders and collaborative partners to reduce suicide in their communities, including investing in implementing ITK's own suicide prevention strategy, released July 27.

According to the framework, the federal government's role in suicide prevention will be to "promote well-being, raise awareness and advance suicide prevention through connections, collaboration, research and best practices."

This means the federal government will have "a very limited role of information exchange and coordination," says
Dr. Laurence Kirmayer, director of the Division of Social and Transcultural Psychiatry at McGill University. "It's one step back from the nitty-gritty."

In 2011, before coming to power, the federal Liberals called for a suicide prevention strategy, rather than a framework. "We need to have a national suicide strategy to reach people in need in every sector of our society," Justin Trudeau, now prime minister but then an opposition MP, told the House of Commons.

The new framework does not provide any immediate help to address poverty and the need for economic development or the "huge amounts of childhood trauma, on-going" including the sexual and physical abuse that often drive suicide, Kirmayer says.

"There's nothing in [the framework] that's offensive - it uses the right language. But you could find that same language in many reports. What really counts is what the government does afterward," Kirmayer says.

One positive note is Health Canada's linking of crisis lines and distress centres.
This is essential if social media providers such as Google and Facebook are to help prevent suicide by directing people who are in crisis to appropriate resources, says Brian Mishara, director of the Centre for Research and Intervention on Suicide and Euthanasia at the University of Quebec at Montreal.

"In this day and age, where so many people are identifying others or themselves as being suicidal on the Internet and are looking for information, it's essential to have a single national number portal or address where people can get help by sending texts or participating in chats or phone calls," Mishara says.

The Canadian Centre for Suicide Prevention also called for a national strategy. "A framework does not identify the necessary jurisdictional mandates or resources; responsibilities are not defined in a clear way, and there are no definitive timelines. A framework does not have the sheer weight or power of an official strategy," the centre said in a statement.

Laura Eggertson, Ottawa, Ont. 